ISSN 0819-2642

ISBN 9780734026576

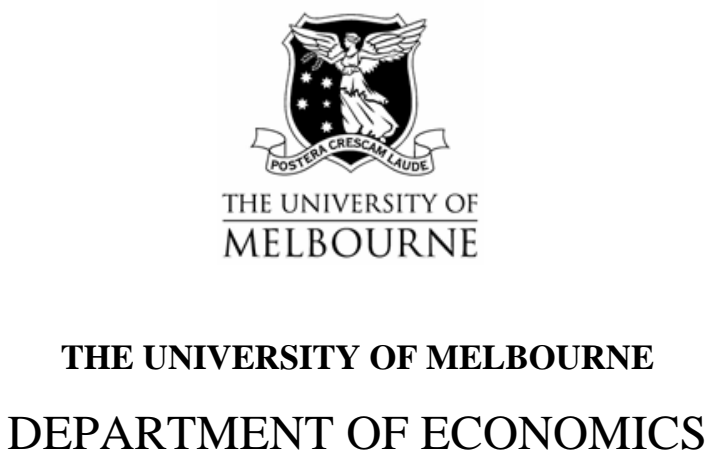

RESEARCH PAPER NUMBER 999

August 2007

\title{
Cooperative R\&D under Uncertainty with Free Entry
}

by

Nisvan Erkal \&

Daniel Piccinin

Department of Economics

The University of Melbourne

Melbourne Victoria 3010

Australia. 


\title{
Cooperative R\&D under Uncertainty with Free Entry ${ }^{1}$
}

\author{
Nisvan Erkal ${ }^{2}$ and Daniel Piccinin ${ }^{3}$
}

First version: November 2006

This version: July 2007

\footnotetext{
${ }^{1}$ We are grateful to Joshua Gans, participants of the conference on Innovation and Competition in the New Economy at the University of Milan, Bicocca and the North American Summer Meetings of the Econometric Society (2007), and seminar participants at the Australian National University (RSSS), Monash University, and the University of New South Wales for their comments. We gratefully acknowledge the financial support of the Faculty of Economics and Commerce at the University of Melbourne.

${ }^{2}$ Department of Economics, University of Melbourne, Victoria 3010, Australia. n.erkal@unimelb.edu.au.

${ }^{3}$ Linklaters LLP, One Silk Street, London, EC2Y 8HQ, United Kingdom. daniel.piccinin@linklaters.com.
} 


\begin{abstract}
In the last few decades, the effects of cooperative R\&D arrangements on innovation and welfare have played an important role in policy making. The goal of this paper is to analyze the effects of cooperative $R \& D$ arrangements in a model with a stochastic $R \& D$ process and output spillovers. Our main innovation is to allow for free entry in both the R\&D race and the product market. To determine the desirability of cooperation in $\mathrm{R} \& \mathrm{D}$ environments, we compare three different ways of organizing $R \& D$ activities: $R \& D$ competition, $R \& D$ cartels, and RJV cartels. In contrast with the literature, we assume that cooperative R\&D arrangements do not have to include all of the firms in the industry. We show that sharing of research outcomes is a necessary condition for the profitability of cooperative R\&D arrangements with free entry. The profitability of RJV cartels depends on their size. The impact of cooperative $R \& D$ arrangements on the aggregate level of innovation depends on whether there are participants in the $R \& D$ race who are a part of the cooperative $R \& D$ arrangement. If some outsiders choose to participate in the $\mathrm{R} \& \mathrm{D}$ race, the aggregate rate of innovation remains unaffected by the formation of a cooperative $\mathrm{R} \& \mathrm{D}$ arrangement. Otherwise, it increases. R\&D cartels may be welfare-improving in cases when they cause the aggregate rate of innovation to increase. In such cases, it may be desirable to subsidize them. Since sharing of $R \& D$ outcomes affects the equilibrium number of firms in the product market after the $R \& D$ race, the consumer welfare effects of RJV cartels are sensitive to the specification of consumer preferences. Subsidies may be desirable in cases of larger RJVs since they are the ones which are less likely to be profitable.
\end{abstract}

JEL classification: L1, L4, O3

Keywords: Cooperative R\&D; Research joint ventures; Free entry; Uncertain R\&D; Technology spillovers. 


\section{Introduction}

This paper analyzes the profit and welfare implications of cooperative $R \& D$ arrangements in an uncertain R\&D environment with free entry. In the last few decades, the observation that $R \& D$ environments are frequently characterized by substantial spillovers and appropriability problems has resulted in a growing interest in the impact of cooperative R\&D arrangements on innovation and welfare. ${ }^{1}$ Despite the possible positive effects of cooperative $R \& D$ arrangements on innovation and welfare, such arrangements pose a difficult problem for policy makers. This is because, as d'Aspremont and Jacquemin (1988) noted nearly twenty years ago, they represent a hybrid of cooperative and non-cooperative relations between firms. Nevertheless, the concern that competing firms in most R\&D environments may have too little incentives to invest in $R \& D$ has caused both the US and Europe to pass legislation for lenient antitrust treatment of research joint ventures (RJVs). ${ }^{2}$

A consistent feature of the literature exploring the effects of cooperative $R \& D$ arrangements is the assumption that the number of firms participating in both the product market and the R\&D process is fixed. ${ }^{3}$ It is desirable to modify this assumption and study the impact of free entry for a number of reasons. First, in many R\&D intensive industries, it may not be realistic to assume that only a limited number of firms can participate in the R\&D process. ${ }^{4}$ When firms cooperate, they affect the expected profits of their rivals and, hence, may induce R\&D race entry or exit. Second, after an R\&D process, when the

\footnotetext{
${ }^{1}$ The discussion of the adverse effects of R\&D spillovers and appropriability problems dates back to Arrow (1962). Empirically, Mansfield et al. (1981) show that $60 \%$ of the patented innovations in their sample were imitated within 4 years. Mansfield (1985) shows that information concerning development decisions leak out to rival firms within about 12 to 18 months.

${ }^{2}$ In the US, the National Cooperative Research and Production Act (NCRPA) of 1993 provides that research and production joint ventures be subject to a 'rule of reason' analysis instead of a per se prohibition in antitrust litigation. In the EU, the Commission Regulation (EC) No 2659/2000 (the EU Regulation) provides for a block exemption from antitrust laws for RJVs, provided that they satisfy certain market share restrictions and allow all joint venture participants to access the outcomes of the research.

${ }^{3}$ For the theoretical literature on research joint ventures, see, for example, Combs (1992), Kamien et al. (1992), Motta (1992), Suzumara (1992), Choi (1993), Vonortas (1994), Ziss (1994), Poyago-Theotoky (1995), Leahy and Neary (1997), Salant and Shaffer (1998), Martin (2002), Amir and Wooders (1999 and 2000), Amir (2000), Kamien and Zang (2000), Anbarci et al. (2002), and Miyagiwa and Ohno (2002), and Hauenschild (2003). See De Bondt (1996) for an excellent survey.

${ }^{4}$ In fact, in the closely related patent race literature, it is common to assume free entry into the R\&D process. See, for example, Loury (1979), Lee and Wilde (1980), Reinganum (1985), and Denicolo (2000).
} 
research outcomes are available to a few firms only, their resulting competitive advantage is likely to result in product market exit. However, as spillovers occur and the research outcomes become available to more firms, this creates incentives for entry into the product market.

Hence, allowing for entry into the R\&D process and the product market introduces new strategic, investment, and welfare implications of cooperative R\&D. Two other important assumptions which distinguish our model are the following. First, as in Miyagiwa and Ohno (2002), we model R\&D as a stochastic process. This assumption is in contrast with the rest of the literature, where, following d'Aspremont and Jacquemin (1988), it is common to model R\&D as a deterministic process. ${ }^{5}$ Second, we assume that cooperative R\&D arrangements do not have to include all the firms in the industry. This is in accordance with industrial practice, but contradicts the previous literature where it is generally assumed that cooperative $R \& D$ arrangements involve all of the firms in the industry. ${ }^{6}$

In the model we consider, an $\mathrm{R} \& \mathrm{D}$ race is followed by oligopolistic product market competition. The winner of the race has exclusive access to a quality-enhancing or costreducing innovation for a limited period of time, after which the innovation spills over to all of the firms in the industry. The duration of the exclusive access represents the speed of outcome spillovers. It is affected by the effectiveness of patent and/or trade secret protection.

Following the literature, we compare the following cooperative R\&D arrangements with the benchmark case of $R \& D$ competition, where firms choose their $R \& D$ intensities independently. We first consider $R \& D$ cartels, where a fixed number of firms set their R\&D investment levels to maximize their joint profits, but do not share their research outcomes. We show that with free entry, such cooperative arrangements are never profitable irrespective of the speed of spillovers. This result stands in stark contrast to the results in the literature, where R\&D cartels are always found to be profitable.

\footnotetext{
${ }^{5}$ In addition to Miyagiwa and Ohno (2002), three other papers that model R\&D as a risky activity are Combs (1992), Choi (1993), Martin (2002), and Hauenschild (2003). Among these papers, our paper is closest to Miyagiwa and Ohno (2002) in terms of its approach and focus.

${ }^{6}$ Kamien and Zang (1993) is a notable exception.
} 
We then consider RJV cartels, where a fixed number of firms choose their investment levels to maximize their joint profits and share their research outcomes. ${ }^{7}$ We show that such cooperative arrangements may be profitable depending on their size. Specifically, small RJV cartels are more likely to be profitable and have higher per-firm investment levels than R\&D competition while large RJV cartels are more likely to be unprofitable and have lower per-firm investment levels than R\&D competition. This implies that sharing of research outcomes is a necessary condition for the profitability of cooperative $R \& D$ arrangements with free entry.

While RJV cartels are always profitable to form in papers where R\&D is modelled as a deterministic process, this is not necessarily the case in papers where $R \& D$ is modelled as a stochastic process. Similar to our results, Miyagiwa and Ohno (2002) and Choi (1993) also qualify the conclusions of the deterministic R\&D literature. Specifically, Miyagiwa and Ohno (2002) show that with uncertain R\&D, the profitability and welfare implications of RJV cartels depend on the level of spillovers and the effect of sharing on industry profits. Choi (1993) finds that RJV cartels may be unprofitable because he assumes that sharing decreases product market payoffs. In comparison with these two papers, we show that when markets are characterized by free entry, the key variable for RJV cartel performance is its size. Hence, our findings can be used to explain why RJVs often do not include all of the firms in an industry and why firms choose to conduct many R\&D projects non-cooperatively.

Our analysis further reveals that the impact of cooperative $R \& D$ arrangements on the aggregate level of innovation depends on whether there are participants in the $R \& D$ race who are not a part of the cooperative $R \& D$ arrangement. If the size of the cartel is such that some outsiders choose to participate in the $R \& D$ race, the aggregate rate of innovation remains unaffected by the formation of a cooperative $R \& D$ arrangement. In such cases, $R \& D$ cartels are still welfare-reducing because they are unprofitable. If the size of the cartel is such that no outsider participants choose to participate in the $R \& D$ race, the aggregate rate of innovation is higher with a cooperative $R \& D$ arrangement than without.

\footnotetext{
${ }^{7}$ Firms do not cooperate in the product market in either of these arrangements.
} 
In such cases, R\&D cartels may be welfare-improving because of their positive impact on consumer welfare.

Whether there are outsider participants in the $R \& D$ race or not, the impact of $R J V$ cartels on consumer welfare depends on consumers' preferences. Although there are more firms in the market with the new technology under an RJV cartel, since this causes more firms with the old technology to exit, consumers also have access to less variety. RJV cartels may be socially desirable depending on which effect dominates, which implies that antitrust policy towards RJV cartels should be sensitive to consumers' preferences.

Hence, our results in general imply that there may be a case for subsidizing R\&D cartels without outsider participants in the R\&D race and RJV cartels with or without outsider participants in the $R \& D$ race because they may be unprofitable but welfare improving. This conclusion is almost unique in the literature where, since $R \& D$ cartels are generally found to be profitable, it is never necessary to subsidize them. ${ }^{8}$ RJV cartels are also found to be more profitable than and welfare superior to $R \& D$ competition in the literature with deterministic R\&D and a fixed number of firms. Moreover, they are most profitable when they include all of the firms in the industry. ${ }^{9}$ This contrasts with our results, which imply that subsidies may be desirable precisely in cases of larger RJVs since they are the ones which are less likely to be profitable. This result also differs from those in the literature with stochastic R\&D and a fixed number of firms, where the welfare implications of RJV cartels depend on the level of spillovers.

The paper proceeds as follows. In Section 2, we present the details of the model. Section 3 presents the product market payoffs which we use in Sections 4, 5, and 6 in the analysis of R\&D competition, R\&D cartels, and RJV cartels respectively. Section 7 explores the welfare and policy implications of the cooperative R\&D arrangements we consider. In Section 8, we extend the analysis by considering the effects of cooperative $R \& D$ arrangements when the cooperating firms face no competition from outsider participants in the $R \& D$ race in

\footnotetext{
${ }^{8}$ For example, Leahy and Neary's (1997) states that 'policy intervention to encourage cooperation is likely to be redundant whether or not it is desirable.'

${ }^{9}$ See Kamien and Zang (1993).
} 
equilibrium. We conclude and make suggestions for future research in Section 9.

\section{The Model}

Consider a continuous-time model where initially symmetric firms compete both in a product market and an R\&D race for a new technology. There is free entry and exit in both the product market and the $R \& D$ race. We assume that the product market is in a long-run equilibrium when an opportunity for a new technology arises. Firms can compete either individually or jointly to be the first to develop the new technology, which may be either a quality-enhancing or a cost-reducing innovation.

We model research activity using a Poisson discovery process. Each firm operates an independent research facility. We allow both incumbent firms and new firms to participate in the $\mathrm{R} \& \mathrm{D}$ race. All participants must incur a one-time entry cost of $S$ to enter the race. The entry cost represents the race-specific fixed-cost expenditure. Firms share a common discount rate $r$. Following Lee and Wilde (1980), we assume that the participants in the race choose an $\mathrm{R} \& \mathrm{D}$ investment $x$ and incur a flow cost $x$ per unit of time. Investment provides a stochastic time of success that is exponentially distributed with hazard rate $h(x)$. We assume that $h^{\prime}(x)>0, h^{\prime \prime}(x)<0$, and $h(0)=0 . \lim _{x \rightarrow 0} h^{\prime}(x)$ is sufficiently large to guarantee an interior equilibrium and $\lim _{x \rightarrow \infty} h^{\prime}(x)=0$.

Following the literature, we consider the following three scenarios. Under R\&D competition, the firms conduct research independently. They make their R\&D and production decisions to maximize their individual payoffs. With an $\mathrm{R} \& \mathrm{D}$ cartel, a set $\mathbf{C}=\{1, \ldots, C\}$ of firms, which are exogenously designated to be part of the cartel, choose their R\&D investments to maximize their joint profits. The cartel members do not share their research outcomes and compete in the product market. With an RJV cartel, a set $\mathbf{J}=\{1, \ldots, J\}$ of firms, which are exogenously designated to be part of the cartel, choose their R\&D investments to maximize their joint profits and all participants in the cartel acquire the new technology when and if one of the cartel's members wins the race. After sharing the new technology, the firms compete in the product market. 
We let $\mathbf{R}=\{1, \ldots, R\}$ denote the set of all firms which choose to participate in the race. In Sections 5 and 6 , we first consider the case when $R$ is strictly greater than the number of firms which cooperate. In other words, we assume that some outsiders always find it profitable to compete in the race. We later relax this assumption in Section 8.

The winner of the race has exclusive rights to the use of the new innovation for a duration of $T$, after which time all firms immediately gain free access to the new technology. As stated in Miyagiwa and Ohno (2002), $T$ can be interpreted as the speed of outcome spillovers. It is likely to be affected by the length and breadth of patent protection as well as the technological ease of reverse engineering.

In the product market, we assume that all firms incur fixed costs of production as long as they continue to produce. In other words, the fixed costs of production are an ongoing expense, not a one-off commitment. Payments on a renewable lease, utility fees, and head office costs are examples of these types of fixed cost. ${ }^{10}$

We make the following assumptions regarding the product market payoffs and use the following notation. We let $N_{t}$ stand for the number of firms active in the product market at time $t$. Firms can choose to be active or inactive in the product market at every instant in the game. During the race, there continues to be free entry into the product market. All firms in the product market earn flow profits $\pi^{o}\left(N_{t}\right)$ net of fixed costs of production, where the superscript $o$ stands for the old technology. However, firms do not need to be active in the product market to be able to participate in the $\mathrm{R} \& \mathrm{D}$ race.

We let $W$ stand for the number of winners at the end of the race. Hence, $N_{t}-W$ stand for the number of active firms with the old technology in the market. After the $R \& D$ race ends but before the innovation spills over to the other firms in the industry, $\pi^{w}\left(W, N_{t}-W\right)$ and $\pi^{f}\left(W, N_{t}-W\right)$ denote the flow profits, net of fixed costs, earned by a firm with the new technology and a firm with the old technology, respectively. Hence, if a single firm wins the race, that firm earns $\pi^{w}\left(1, N_{t}-1\right)$ while if an RJV cartel wins the race, each member of the RJV cartel earns $\pi^{w}\left(J, N_{t}-J\right)$. We assume

\footnotetext{
${ }^{10}$ This can be seen as a long run approximation to an industry where some costs are sunk in the short run.
} 
Assumption $1 \pi^{w}\left(W, N_{t}-W\right)>\pi^{f}\left(W, N_{t}-W\right)$.

Hence, the firms with the new technology earn more than the firms with the old technology. Such an assumption holds in standard Cournot and differentiated good Bertrand models. After $T$ periods, the innovation spills over and the firms' flow profits become $\pi^{n}\left(N_{t}\right)$ if they are active, where the superscript $n$ stands for the new technology, and zero otherwise.

We assume that all profit functions are decreasing in the level of competition, represented in the following two assumptions by the number of firms with the new technology and the total number of firms in the market, respectively.

Assumption $2 \pi^{w}\left(W, N_{t}-W\right)$ and $\pi^{f}\left(W, N_{t}-W\right)$ are decreasing in $W$.

Assumption 3 All product market payoffs are decreasing in $N_{t}$.

To summarize, the timing of the game is as follows.

Stage 1: The product market is in a long-run equilibrium. An opportunity for the development of a new technology arises.

Stage 2: The cooperative R\&D structure is determined exogenously.

Stage 3: All firms, whether active in the product market or not, decide whether to incur a fixed cost $S$ to enter the $R \& D$ race. Those firms which are active in the product market earn flow profits $\pi^{o}\left(N_{t}\right)$.

Stage 4: The $R \& D$ race ends as soon as one of the firms develops the new technology. After a firm wins the race but before spillovers occur, all firms with the new technology earn a flow payoff of $\pi^{w}\left(W, N_{t}-W\right)$ while all other active firms earn $\pi^{f}\left(W, N_{t}-W\right)$ for duration $T$.

Stage 5: After a duration of $T$, all firms gain access to the new technology and earn flow payoffs of $\pi^{n}\left(N_{t}\right)$ if they produce.

We solve for the subgame perfect equilibrium of this game using backward induction. 


\section{Product Market Competition}

To determine the payoffs to the winners and losers of the $R \& D$ race, we start the analysis by considering the product market competition after the race has ended. Note that the equilibrium number of firms in the product market changes only when there is a change in the technological environment. Hence, after the innovation spills over to all of the firms in the industry, entry occurs until $\pi^{n}\left(N_{t}\right)=0$ and the firms earn zero profits thereafter.

There is exit from the product market immediately after the race ends since the presence of one or more firms with a better technology makes it unprofitable for (at least) some of the firms that were in the market before the race came to an end to continue to produce. If the innovation is not drastic, the remaining firms without access to the new technology continue to produce using the old technology. Since exit happens instantaneously, the remaining firms in the market immediately start to earn either $\pi^{w}\left(W, N_{t}-W\right)$ or $\pi^{f}\left(W, N_{t}-W\right)$. Hence, after the $\mathrm{R} \& \mathrm{D}$ race ends but before spillovers take place, there are $W$ firms in the market with the new technology. $N_{t}$ is equal to $W$ if the innovation is drastic. If the innovation is not drastic, the number of firms which are producing using the old technology is determined by $\pi^{f}\left(W, N_{t}-W\right)=0$.

\section{R\&D Competition}

In this section we consider the benchmark case where the firms conduct R\&D independently. We show that there exists a free entry equilibrium to the R\&D competition game, and characterize the investment choices and the number of firms in this equilibrium.

With a Poisson discovery process, the probability that there has not been a discovery until time $t$ is given by exp $\left[-\sum_{i \in \mathbf{R}} h\left(x_{i}\right) t\right]$. Conditional on this probability, each participant earns a flow profit of $\left(\pi^{o}\left(N_{t}\right)-x_{i}\right) d t$ during the interval $d t$ if they are active in the product market and $-x_{i} d t$ otherwise. Since the product market is in a long-run equilibrium at the beginning of the game and the decision to be active in the product market is independent of the decision to be active in the $\mathrm{R} \& \mathrm{D}$ race, the number of firms in the market, $N_{t}$, does not change until the race ends and is given by $\pi^{o}\left(N_{t}\right)=0$. 
If firm $i$ innovates during the interval $d t$, its earnings for the period $T$ are

$$
\int_{0}^{T} e^{-r t} \pi^{w}\left(1, N_{t}-1\right) d t
$$

As explained in Section 3, after the innovation arrives, $N_{t}$ does not change until the end of the period $T$. Hence, using $N^{R}$ to denote the equilibrium number of firms in the product market during this time period, we can re-write (1) as

$$
\frac{L}{r}=\frac{\left(1-e^{-r T}\right) \pi^{w}\left(1, N^{R}-1\right)}{r}
$$

If another firm innovates during the interval $d t$, firm $i$ 's profit is equal to zero due to the assumption of free entry and exit. Even after the spillovers occur and firm $i$ gains access to the new technology, since entry takes place until the product market profits are driven to zero, firm $i$ continues to make zero.

We can now write down the present discounted value of the sum of firm $i$ 's expected profits over time as

$$
V_{i}=\int_{0}^{\infty} e^{-\Sigma h\left(x_{i}\right) t} e^{-r t}\left[h\left(x_{i}\right) \frac{L}{r}-x_{i}\right] d t-S=\frac{h\left(x_{i}\right) \frac{L}{r}-x_{i}}{r+h\left(x_{i}\right)+\alpha_{i}}-S,
$$

where $\alpha_{i}=\sum_{j \neq i} h\left(x_{j}\right)$ stands for the aggregate hazard rate of the rival firms.

Given the memoryless nature of the Poisson process, firm $i$ takes $\alpha_{i}$ as given and chooses $x_{i}$ to maximize this payoff function at every point in time during the race. The first-order condition is

$$
h^{\prime}\left(x_{i}\right)\left[L+x_{i}+\frac{L}{r} \alpha_{i}\right]-\left[r+h\left(x_{i}\right)+\alpha_{i}\right]=0 .
$$

The second-order condition is

$$
h^{\prime \prime}\left(x_{i}\right)\left[L+x_{i}+\frac{L}{r} \alpha_{i}\right]<0,
$$

which is always satisfied because of the concavity assumption on $h\left(x_{i}\right)$. Hence, the firstorder condition implicitly defines the optimal choice of $x_{i}$ as a function of the rival firms' investment choices. 
Since all of the firms are symmetric, we look for a symmetric equilibrium. The equilibrium per-firm investment levels and number of firms can be determined by solving the first-order condition of a generic firm and the zero profit condition simultaneously. To show that there exists a free entry equilibrium, we need to show that the expected profits at the beginning of the $\mathrm{R} \& \mathrm{D}$ race are decreasing in the number of firms.

For a profit-maximizing firm, we have

$$
\frac{d V_{i}}{d R}=\frac{\partial V_{i}}{\partial \alpha_{i}} \frac{\partial \alpha_{i}}{\partial R}
$$

since $\frac{\partial V_{i}}{\partial x_{i}}=0$. The following lemma states how a profit maximizing firm's payoff changes with $\alpha_{i}$.

Lemma 1 The expected payoff of a profit maximizing firm $i$ that is active in the R\&D race decreases monotonically with the value of $\alpha_{i}$.

Proof. Applying the envelope theorem to the maximum value of (3) gives

$$
\frac{-\left[h\left(\widehat{x}\left(\alpha_{i}\right)\right) \frac{L}{r}-\widehat{x}\left(\alpha_{i}\right)\right]}{\left[r+h\left(\widehat{x}\left(\alpha_{i}\right)\right)+\alpha_{i}\right]^{2}}<0 .
$$

To determine the sign of $\frac{\partial \alpha_{i}}{\partial R}$, taking $R$ as given, let $\bar{x}$ represent the symmetric solution to the first-order conditions. It satisfies the following equation.

$$
\bar{x}=\widehat{x}((R-1) h(\bar{x})),
$$

where $\widehat{x}$ stands for the best response function. Note that at a symmetric equilibrium, $\alpha_{i}=\bar{\alpha}=(R-1) h(\bar{x})$. The corresponding per-firm profit level for a given value of $R$ is

$$
\bar{V}(R)=\frac{h(\bar{x}) \frac{L}{r}-\bar{x}}{r+R h(\bar{x})}-S .
$$

We first analyze the slope of the best response function of firm $i$. Using the implicit function theorem gives us

$$
\frac{\partial \widehat{x}\left(\alpha_{i}\right)}{\partial x_{j}}=-\frac{h^{\prime}\left(x_{j}\right)\left[h^{\prime}(\widehat{x}) \frac{L}{r}-1\right]}{h^{\prime \prime}(\widehat{x})\left[L+\widehat{x}+\frac{L}{r} \alpha_{i}\right]} .
$$


Note that the first-order condition given in (4) can be re-written as

$$
\left[h^{\prime}\left(x_{i}\right) \frac{L}{r}-1\right]\left[r+h\left(x_{i}\right)+\alpha_{i}\right]-h^{\prime}\left(x_{i}\right)\left[h\left(x_{i}\right) \frac{L}{r}-x_{i}\right]=0 .
$$

From (3), we have $\pi_{i}+S=\frac{\left[h^{\prime}\left(x_{i}\right) \frac{L}{r}-1\right]}{h^{\prime}\left(x_{i}\right)}$. Hence, we can re-write (9) as

$$
\frac{\partial \widehat{x}\left(\alpha_{i}\right)}{\partial x_{j}}=-\frac{h^{\prime}\left(x_{j}\right) h^{\prime}(\widehat{x})\left(\pi_{i}+S\right)}{h^{\prime \prime}(\widehat{x})\left[L+\widehat{x}+\frac{L}{r} \alpha_{i}\right]},
$$

which is $>0$ since $h^{\prime \prime}\left(x_{i}\right)<0$. Hence, the investment choices of the firms are strategic complements.

We next show that $\bar{x}$ is increasing in $R$. Using (7) we get

$$
\frac{\partial \bar{x}}{\partial R}=\frac{\partial \widehat{x}((R-1) h(\bar{x}))}{\partial R}=\frac{\frac{\partial \widehat{x}}{\partial(R-1) h(\bar{x})} h(\bar{x})}{1-\frac{\partial \widehat{x}}{\partial(R-1) h(\bar{x})}(R-1) h^{\prime}(\bar{x})} .
$$

The numerator of this expression is positive because the investment decisions of the firms are strategic complements. Following Lee and Wilde (1980), we define the expression in the denominator as a stability condition. Hence, it is also positive and $\frac{\partial \bar{x}}{\partial R}>0$. This implies $\frac{\partial \bar{\alpha}}{\partial R}>0$ and we can now state the following result.

Proposition 1 There exists a free entry equilibrium to the RED competition game where the equilibrium number of firms, $R^{*}$, is determined by $V^{*}=\bar{V}\left(R^{*}\right)=0$. Each of these $R^{*}$ firms invests $x^{*}=\bar{x}\left(R^{*}\right)$.

\section{$5 \quad$ R\&D Cartel}

In this section, we compare the case of $\mathrm{R} \& \mathrm{D}$ competition with the case where a group of $C$ firms form an R\&D cartel. The cartel members participate in the R\&D race by choosing their investment levels to maximize their joint payoffs, but they do not share their research outcomes. Hence, as in the case of R\&D competition, each firm $i$ in the cartel earns $\frac{L}{r}$ only in the case when it wins the race. We assume that due to free entry in the $R \& D$ race, the cartel participants still face competition from outsider participants in the race. 
The joint payoffs of the cartel participants are given by

$$
\sum_{i \in \mathbf{C}}\left(\frac{h\left(x_{i}\right) \frac{L}{r}-x_{i}}{r+\sum_{j \in \mathbf{C}} h\left(x_{j}\right)+\sum_{k \notin \mathbf{C}} h\left(x_{k}\right)}-S\right),
$$

where $\mathbf{C}$ is the set of firms participating in the R\&D cartel, $L$ is as defined in (2), and the last term in the denominator, $\sum_{k \notin \mathbf{C}} h\left(x_{k}\right)$, stands for the sum of the hazard rates of the outsider participants in the race. Each outsider maximizes the payoff function given in (3).

We look for a symmetric equilibrium, where each cartel member invests $x^{C}$, each outsider participant invests $x^{O}$, and $R^{C}$ stands for the number of participants in the R\&D race. These values, if an equilibrium exists, can be found by solving the first-order conditions given by

$$
h^{\prime}\left(x^{C}\right)\left[L+C x^{C}+\frac{L}{r}\left(R^{C}-C\right) h\left(x^{O}\right)\right]-\left[r+C h\left(x^{C}\right)+\left(R^{C}-C\right) h\left(x^{O}\right)\right]=0
$$

and

$$
h^{\prime}\left(x^{O}\right)\left[L+x^{O}+\frac{L}{r}\left[\begin{array}{c}
\left(R^{C}-C-1\right) h\left(x^{O}\right) \\
+C h\left(x^{C}\right)
\end{array}\right]\right]-\left[\begin{array}{c}
r+C h\left(x^{C}\right) \\
+\left(R^{C}-C\right) h\left(x^{O}\right)
\end{array}\right]=0,
$$

and the zero-profit condition given by

$$
\frac{h\left(x^{O}\right) \frac{L}{r}-x^{O}}{r+C h\left(x^{C}\right)+\left(R^{C}-C\right) h\left(x^{O}\right)}-S=0
$$

simultaneously. ${ }^{11}$

The following proposition establishes that there exists a free entry equilibrium with an $\mathrm{R} \& \mathrm{D}$ cartel. As in the case of $\mathrm{R} \& \mathrm{D}$ competition, the result relies on a stability condition specified in the Appendix.

Proposition 2 There exists a free entry equilibrium with an R\&D cartel.

Proof. See Section 1 in the Appendix.

\footnotetext{
${ }^{11}$ It is straightforward to verify that the second-order conditions hold because of the concavity assumption on $h\left(x_{i}\right)$.
} 
To determine the profitability of $R \& D$ cartels and their impact on innovation, we start by comparing the per-firm investment level under R\&D competition with the per-firm investment level in an $R \& D$ race with an $R \& D$ cartel. The following proposition establishes that while the cartel participants reduce their per-firm investment level, the outsider participants invest the same amount as they do under R\&D competition.

Proposition 3 In equilibrium, the per-firm investment level of the RED cartel participants, $x^{C}$, is lower than the per-firm investment level under R\&D competition, $x^{*}$. The investment level of outsider firms in the R\&D race with an RED cartel, $x^{O}$, is equal to $x^{*}$.

Proof. See Section 2 in the Appendix.

With free entry in the product market, $R \& D$ investments always confer a net negative externality on rivals. Outcome spillovers do not provide any benefit to the firms that lose the $R \& D$ race because any future rents that could be earned by using the new technology are dissipated through entry into the product market. This transforms the $\mathrm{R} \& \mathrm{D}$ race into a winner-takes-all game. Since the R\&D cartel members internalize the negative externality they impose on each other, they invest less than the outsider participants in the race.

In the proof of Proposition 3, we use Lemma 1 to show that all outsider firms invest the same amount in the presence of an R\&D cartel as they do under R\&D competition. Since in both cases the outsider firms earn zero profits in equilibrium, Lemma 1 implies that they face the same profit maximization problem and choose the same solution.

Comparing these results with those of Miyagiwa and Ohno (2002) reveals the importance of the assumption of free entry. If there are barriers to entry in the product market, the losers of the $R \& D$ race still get a chance to benefit from the innovation after spillovers happen. For sufficiently small values of $T$ (i.e., for sufficiently rapid spillovers), this positive spillover effect outweighs the negative competitive effect mentioned above and, thus, R\&D investments confer a net positive externality on the rival firms. Hence, Miyagiwa and Ohno (2002) find that for sufficiently small $T$ values, when firms form an R\&D cartel that allows them to internalize these positive externalities, they end up increasing their investment 
levels above the investment level under R\&D competition. ${ }^{12}$

Ultimately, what is important is the impact of the $R \& D$ cartel on the aggregate arrival rate of innovation. The conclusion in the literature is that $\mathrm{R} \& \mathrm{D}$ cartels decrease the aggregate rate of innovation for sufficiently low spillovers and increase it for sufficiently high spillovers. This follows immediately from the per-firm investment results discussed above since it is generally assumed that all firms participate in the R\&D cartel. In our context, due to the assumption of free entry, one cannot readily use the results on the changes in the individual investment levels to determine the impact of $R \& D$ cartels on the aggregate rate of innovation. Instead, we proceed in the following way. Since there are outsider firms in the $\mathrm{R} \& \mathrm{D}$ race, the aggregate arrival rate of innovation is equal to $h\left(x_{i}\right)+\alpha_{i}$ from the perspective of any outsider firm $i$. Since the outsider firms earn zero profits both with an $\mathrm{R} \& \mathrm{D}$ cartel and under $\mathrm{R} \& \mathrm{D}$ competition, Lemma 1 implies that $\alpha_{i}$ is the same in both cases. From Proposition 3 we know that $x_{i}=x^{*}$ in both cases also. Hence, the aggregate rate of innovation is the same in both cases. This implies that the total number of firms participating in the $R \& D$ race must be higher with an $R \& D$ cartel than under $R \& D$ competition. That is, since $x_{C}<x^{O}$ and $x^{O}=x^{*}$, more firms must be investing with an R\&D cartel to achieve the same level of aggregate innovation as under R\&D competition.

The following proposition summarizes this discussion.

Proposition 4 In an RESD environment with an REDD cartel,

(i) the aggregate arrival rate of innovation is the same as under RED competition;

(ii) a higher number of firms participate in the R\&D race than under R\&D competition.

With a fixed number of participants in the $\mathrm{R} \& \mathrm{D}$ race, the formation of an $\mathrm{R} \& \mathrm{D}$ cartel would cause the outsider firms' expected profits to increase because the R\&D cartel members invest less than they do under $R \& D$ competition. With free entry into the $R \& D$ race, the increase in the expected profits of the outsider firms invites entry into the race until

\footnotetext{
${ }^{12}$ This result is in line with the results of the other papers in the literature that model R\&D as a deterministic process. If the rate of spillovers is sufficiently high, the positive externality they generate outweighs the negative externality generated by competition. See, for example, d'Aspremont and Jacquemin (1988) and Kamien et al. (1992).
} 
the expected profits are driven down to zero. Proposition 4 implies that the entrants' investment level exactly compensates for the decrease in the investment level of the R\&D cartel members.

We finally evaluate the profitability of R\&D cartels.

Proposition 5 All RESD cartels are unprofitable.

Proof. Each member of the R\&D cartel and each outsider firm face $R^{C}-1$ competitors in equilibrium. Of these, $R^{C}-2$ competitors are the same for these two type of firms. However, an R\&D cartel member's $R^{C}-1$ th competitor is an outsider firm investing $x^{*}$ while the outsider firm's $R^{C}-1$ th competitor is an R\&D cartel member investing $x^{C}<x^{*}$. Hence, the value of $\alpha_{i}$ faced by a member of the $\mathrm{R} \& \mathrm{D}$ cartel is higher than the value of $\alpha_{i}$ faced by an outsider. By Lemma 1, this implies that the outsider firm would earn a higher profit than the R\&D cartel member if both firms maximized their individual profits. The R\&D cartel member earns even less since it does not maximize its individual profits.

This result also contrasts with the results in the previous studies of R\&D cartels, which consistently find that the joint profits of the firms within an R\&D cartel are higher than their joint profits under R\&D competition. ${ }^{13}$ In our analysis, free entry into the R\&D race makes otherwise profitable $R \& D$ cartels unprofitable. This is because the members of an $R \& D$ cartel earn less than the outsider participants in the race because of a free rider effect. $^{14}$ The outsider firms benefit from the lower investment of the cartel members because it increases their probability of success. Since the outsiders earn zero and the R\&D cartel members earn less, the R\&D cartels are unprofitable in equilibrium. ${ }^{15}$

\footnotetext{
${ }^{13}$ Again, see, for example, d'Aspremont and Jacquemin (1988), Kamien et al. (1992), and Miyagiwa and Ohno (2002).

${ }^{14} \mathrm{~A}$ similar kind of free rider effect exists in the mergers literature. See Salant et al. (1983) and Deneckere and Davidson (1985).

${ }^{15}$ Erkal and Piccinin (2006) and Davidson and Mukherjee (2007) show that free entry in the product market makes otherwise profitable product market mergers unprofitable.
} 


\section{RJV Cartel}

We next consider the case where an exogenously-determined group of $J$ firms participate in the $\mathrm{R} \& \mathrm{D}$ race by forming an $\mathrm{RJV}$ cartel. The firms make their $\mathrm{R} \& \mathrm{D}$ decisions jointly and gain immediate access to the new technology in the event that any one of them wins the race.

The RJV cartel's expected payoff is

$$
\sum_{i \in \mathbf{J}}\left(\frac{h\left(x_{i}\right) \frac{L^{J}}{r}+\sum_{k \neq i, k \in \mathbf{J}} h\left(x_{k}\right) \frac{L^{J}}{r}-x_{i}}{r+h\left(x_{i}\right)+\sum_{k \neq i, k \in \mathbf{J}} h\left(x_{k}\right)+\sum_{l \notin \mathbf{J}} h\left(x_{l}\right)}-S\right),
$$

where the last term in the denominator stands for the sum of the hazard rates of the outsider participants in the race. $L^{J}$ is given by

$$
L^{J}=\left(1-e^{-r T}\right) \pi^{w}\left(J, N^{J}-J\right)
$$

where $N^{J}$ stands for the equilibrium number of firms in the product market during the period $T$. The flow profit the firms earn if they win the race, $\pi^{w}\left(J, N^{J}-J\right)$, depends on the number of participants in the RJV cartel because the winner shares the new technology with the rest of the cartel, which determines the number of firms in the product market with the new technology for the period $T$.

We start the analysis by establishing that, as in the case of $R \& D$ competition and R\&D cartels, there exists a free entry equilibrium with an RJV cartel where each cartel member invests $x^{J}$, each outsider participant invests $x^{O}$, and $R^{J}$ stands for the number of participants in the $R \& D$ race. In equilibrium, these values must satisfy the first-order conditions given by

$$
J h^{\prime}\left(x^{J}\right)\left[L^{J}+x^{J}+\frac{L^{J}}{r}\left(R^{J}-J\right) h\left(x^{O}\right)\right]-\left[r+J h\left(x^{J}\right)+\left(R^{J}-J\right) h\left(x^{O}\right)\right]=0
$$

and

$$
h^{\prime}\left(x^{O}\right)\left[L+x^{O}+\frac{L}{r}\left[\begin{array}{c}
\left(R^{J}-J-1\right) h\left(x^{O}\right) \\
+J h\left(x^{J}\right)
\end{array}\right]\right]-\left[\begin{array}{c}
r+J h\left(x^{J}\right) \\
+\left(R^{J}-J\right) h\left(x^{O}\right)
\end{array}\right]=0,
$$


and the zero-profit condition given by

$$
\frac{h\left(x^{O}\right) \frac{L}{r}-x^{O}}{r+J h\left(x^{J}\right)+\left(R^{J}-J\right) h\left(x^{O}\right)}-S=0 .{ }^{16}
$$

As in the case of $R \& D$ competition and $R \& D$ cartels, the result relies on a stability condition specified in the Appendix.

Proposition 6 There exists a free entry equilibrium with an RJV cartel.

Proof. See Section 3 in the Appendix.

The difference between an RJV cartel and an R\&D cartel is the product market payoff the members receive when one of the cartel participants wins the $R \& D$ race. Hence, to determine the profitability of RJV cartels and their impact on innovation, we first explore how the equilibrium per-firm investment and profit levels of an RJV cartel change with $L^{J}$. While analyzing the impact of an increase in $L^{J}$, one has to take into account its effect on the entry and investment decisions of the outsider participants in the $\mathrm{R} \& \mathrm{D}$ race also. We have the following result.

Lemma 2 The equilibrium per-firm investment and profit levels of an RJV cartel of size $J$ are monotonically increasing in $L^{J}$.

Proof. See Section 4 in the Appendix.

We next evaluate the performance of an RJV cartel for low and high values of $L^{J}$ to be able to draw conclusions for the range of possible RJV cartel effects. The following lemma presents results for the cases when $L^{J}=\frac{L}{J}$ and $L^{J}=L$.

Lemma 3 If $L^{J}=\frac{L}{J}$, in equilibrium the members of the RJV cartel invest less than $x^{*}$, the per firm investment level under REBD competition, and make a lower profit than they would under R\&D competition. If $L^{J}=L$, in equilibrium the members of the RJV cartel invest more than $x^{*}$ and make a higher profit than they would under REDD competition.

\footnotetext{
${ }^{16} \mathrm{It}$ is straightforward to verify that the second-order conditions hold because of the concavity assumption on $h\left(x_{i}\right)$.
} 
Proof. See Section 5 in the Appendix.

In the comparison of the per-firm investment levels in an environment with an RJV cartel and in an environment with R\&D competition, two effects play a role. First, while firms inflict negative externalities on each other under R\&D competition, members of RJV cartels confer positive externalities on each other because they share their research outcomes. Joint profit maximization allows the cartel participants to internalize these positive externalities, which causes the per-firm investment level to increase. Second, the per-firm returns to winning when the firms are part of an RJV cartel differ from those under R\&D competition because when a member of the RJV cartel wins the R\&D race, all its members have access to the new technology. When $L^{J}=\frac{L}{J}$, the returns with an RJV cartel are lower than the returns under R\&D competition, which are equal to $L$. This affects the per-firm investment level with an RJV cartel adversely. Lemma 3 implies that when $L^{J}=\frac{L}{J}$, this negative effect dominates the positive effect and, hence, the members of the RJV cartel invest less than they would under $R \& D$ competition and make lower profits. On the other hand, when $L^{J}=L$, the returns to winning are the same under both arrangements and the first effect causes the per-firm investment and profit level to be higher with an RJV cartel.

In papers which model $\mathrm{R} \& \mathrm{D}$ as a deterministic process, $\mathrm{RJV}$ cartels are always profitable and result in an increase in the level of investment because of spillovers and joint-profit maximization. In contrast, in papers which model $R \& D$ as a stochastic process, RJV cartels may not always be profitable. Choi (1993) finds that RJV cartels may be unprofitable because in his model sharing of R\&D outcomes increases product market competition. Such an assumption is not required for our results. Indeed, in our framework, it is possible for sharing of $R \& D$ outcomes to increase industry profits since it can also reduce the total number of participants in the product market. ${ }^{17}$ RJV cartels may be unprofitable even in those cases when sharing increases industry profits because of free entry in the R\&D race. In contrast, Miyagiwa and Ohno (2002) find that if industry profits increase with the sharing a new technology, the members of a RJV cartel must be making higher profits than

\footnotetext{
${ }^{17}$ Note that even though we allow for outsiders and entry, industry profits are still equal to the total profits made by the cartel members since the outsiders make zero profits.
} 
they would under R\&D competition.

As far as RJV cartels and R\&D cartels are concerned, we point out in the proof of Lemma 3 that when $L^{J}=\frac{L}{J}$, an RJV cartel and an R\&D cartel of the same size would result in the same level of per-firm investment and would earn the same profits in equilibrium. Together with Lemma 2 this implies that for $L^{J}>\frac{L}{J}$, firms make higher investments and higher profits in an RJV cartel than in an R\&D cartel.

Using Lemmas 2 and 3, we can establish the existence of two critical values, $\widehat{L}^{J}(J)$ and $\widetilde{L}^{J}(J)$, such that the per-firm profit and investment levels will be higher with an RJV cartel than under R\&D competition if $L^{J}>\widehat{L}^{J}(J)$ and $L^{J}>\widetilde{L}^{J}(J)$ respectively. Establishing that $\widehat{L}^{J}(J)<\widetilde{L}^{J}(J)$, the following proposition presents a characterization of the performance of R\&D environments with RJV cartels based on $L^{J}$.

Proposition 7 For values of $J$ such that $L^{J}>\widetilde{L}^{J}(J) \in\left(\widehat{L}^{J}(J), L\right)$, the members of an RJV cartel invest higher amounts and make higher profits than they would under RGD competition. For values of $J$ such that $L^{J} \in\left[\widehat{L}^{J}(J), \widetilde{L}^{J}(J)\right]$, the members of an RJV cartel invest lower amounts and make higher profits than they would under R\&D competition. For values of $J$ such that $L^{J}<\widehat{L}^{J}(J) \in\left(\frac{L}{J}, L\right)$, the members of an $R J V$ cartel invest lower amounts and make lower profits than they would under RED competition.

Proof. See Section 6 in the Appendix.

Proposition 7 implies that if the per-firm investment level is higher with an RJV cartel, it must be the case that the per-firm profit level is also higher. The reason that the firms may be making higher profits even if their investment levels are lower than they would be if they were not cooperating is that they benefit from each other's investment levels. Being a member of the RJV cartel provides them with insurance in that they start to earn $L^{J}$ as soon as any member of the cartel successfully develops the new technology. Hence, with lower individual investment amounts, they can still have higher individual expected payoff levels than they would under R\&D competition.

Proposition 7 allows us to link RJV cartel size to RJV cartel performance if we impose a weak condition on the relationship between $L^{J}$ and $J$. 
Assumption $4 \frac{\partial L^{J}(J)}{\partial J} \leqslant 0$ and $\lim _{J \rightarrow \infty} L^{J}(J)<0$.

Assumption 4 states that the returns from winning the $R \& D$ race are weakly decreasing in the size of the RJV cartel. This assumption would be satisfied in many standard models of oligopolistic competition with free entry. In the next example, we illustrate this with the specific case of homogeneous good Cournot competition. Additional examples can be given using models of logit and CES demand systems. ${ }^{18}$

Example 1 Let inverse demand be given by $P(Q)=100-Q$. Suppose the firms with the new technology has a marginal cost of zero and the firms with the old technology face $M C=1$. The fixed cost of production is 9 for all firms.

For given levels of $N$ and $J$, total quantity produced is

$$
Q=\frac{100 J+(N-J) 99}{(N+1)}
$$

Since the firms producing with the old technology make $\left(\frac{99-J}{(N+1)}\right)^{2}-9, N=\max \left\{\frac{90-J}{9}, J\right\}$ in a free entry equilibrium. Note that $N \geqslant J$ for $J \leqslant 9$. Hence, for $J \leqslant 9$, each cartel member makes

$$
\left(\frac{N+100-J}{(N+1)}\right)^{2}-9=91
$$

and $L^{J}=L$. In a model with entry and exit, for $J \leqslant 9$, an increase in $J$ has two opposing effects on the the product market profits of the cartel members. While having more rivals which have access to the new technology puts more competitive pressure on the cartel members, it also causes more of the firms which do not have access to the new technology to exit. The above result implies that these two effects exactly balance each other.

For sufficiently large values of $J$, i.e., for $J>9$, no firm finds it profitable to participate in the market using the old technology. Hence, each cartel member's profit, given by $\left(\frac{100}{(J+1)}\right)^{2}-9$, strictly decreases with $J$.

Given Assumption 4, the following corollary follows immediately from Proposition 7.

\footnotetext{
${ }^{18}$ More generally, it can be shown that Assumption 4 would be satisfied in any model of Bertrand competition with a separable indirect utility function or Cournot competition with a separable direct utility function.
} 
Corollary 1 The members of a sufficiently small RJV cartel invest higher amounts and make higher profits than they would under RED competition. The members of an intermediatesized RJV cartel invest lower amounts and make higher profits than they would under REDD competition. The members of a sufficiently large RJV cartel invest lower amounts and make lower profits than they would under REDD competition.

The per-firm payoff to winning the R\&D race, $L^{J}$, depends on the RJV cartel's size, $J$. For sufficiently large RJV cartels such that $L^{J}<\widehat{L}^{J}(J)$, these payoffs are lower because the innovation is shared amongst more firms in the product market, which increases the product market competition. Corollary 1 compares RJV cartels of various size categories with the benchmark of $\mathrm{R} \& \mathrm{D}$ competition. It provides an explanation for why relatively small RJV cartels may form - these may be more profitable than larger ones. Indeed, some large RJV cartels may be unprofitable because they include too many firms.

This analysis makes an important contribution to the literature since studies of cooperative arrangements in $R \& D$ environments generally assume that all of the firms in the industry participate in the cooperative structure. Hence, they do not analyze the impact of RJV cartel size on performance. An exception is Kamien and Zang (1993). Using a model with barriers to entry and a deterministic R\&D process, they find that if the firms in an industry form competing RJV cartels, the resulting investment level may be higher than if all of the firms were members of the same grand RJV cartel. However, firms always make higher profits with a grand RJV than with competing RJVs. In contrast, we find that smaller RJV cartels may be more profitable than larger RJV cartels. The difference is due to entry. In Kamien and Zang (1993), profits are higher with a larger RJV because the cartel members face less competition during the R\&D process. In our case, having a larger RJV does not necessarily result in less competition in the R\&D process because of the free entry and exit of outsider firms. Smaller RJVs may be more profitable because although the benefits from joint profit maximization are lower with a smaller RJV, each firm expects to earn a higher amount in the product market.

Finally, we turn our attention to the impact of RJV cartels on the aggregate arrival 
rate of innovation. Since the analysis is identical to the analysis in the case of R\&D cartels, which precedes Proposition 4, we do not repeat it here. We get the following result.

Proposition 8 The aggregate arrival rate of innovation with an RJV cartel is the same as under R\&D competition.

This result differs from the results in the literature with barriers to entry. In the deterministic R\&D literature, RJV cartels always increase the aggregate arrival rate of innovation. In contrast, Miyagiwa and Ohno (2002) show that with a stochastic R\&D process, the impact of RJV cartels on the aggregate arrival rate of innovation depends on the level of spillovers and the effect of sharing on industry profits. Our results extend those of Miyagiwa and Ohno (2002) by pointing out that with free entry, even if the per-firm investment level is different from the $\mathrm{R} \& \mathrm{D}$ competition level, the aggregate arrival rate of innovation remains the same.

\section{$7 \quad$ Welfare and Policy Implications}

We next turn our attention to the welfare and policy implications of the cooperative R\&D arrangements that we have considered. We define welfare as the sum of consumer welfare and producer surplus. This implies that since the firms make zero profits in equilibrium, welfare under R\&D competition is equal to

$$
W^{*}=\frac{R^{*} h\left(x^{*}\right) \frac{\Omega^{1}}{r}+\omega^{o}}{r+R^{*} h\left(x^{*}\right)}
$$

where

$$
\frac{\Omega^{1}}{r}=\frac{\left(1-e^{-r T}\right) \omega^{1}+e^{-r T} \omega^{n}}{r}
$$

stands for the consumer welfare level after the race ends and one firm has the new technology for duration $T . \omega^{o}, \omega^{1}$ and $\omega^{n}$ stand for the flow consumer welfare when no firms, only one firm, and all firms have access to the new technology, respectively.

Similarly, the equilibrium welfare expressions with an R\&D and RJV cartel are

$$
W^{C}=\frac{\left[C h\left(x^{C}\right)+\left(R^{C}-C\right) h\left(x^{*}\right)\right] \frac{\Omega^{1}}{r}+\omega^{o}+C\left[h\left(x^{C}\right) \frac{L}{r}-x^{C}\right]}{r+C h\left(x^{C}\right)+\left(R^{C}-C\right) h\left(x^{*}\right)}-C \cdot S
$$


and

$$
W^{J}=\frac{J h\left(x^{J}\right) \frac{\Omega^{J}}{r}+\left(R^{J}-J\right) h\left(x^{*}\right) \frac{\Omega^{1}}{r}+\omega^{o}+J\left[h\left(x^{J}\right) \frac{J L^{J}}{r}-x^{J}\right]}{r+J h\left(x^{J}\right)+\left(R^{J}-J\right) h\left(x^{*}\right)}-J \cdot S,
$$

respectively. Defining $\omega^{J}$ as the flow consumer welfare when $J$ firms have the new technology,

$$
\frac{\Omega^{J}}{r}=\frac{\left(1-e^{-r T}\right) \omega^{J}+e^{-r T} \omega^{n}}{r}
$$

stands for the consumer welfare level after the race ends and $J$ firms have the new technology for duration $T$.

These expressions show that since we evaluate welfare from an ex ante perspective, the aggregate arrival rate of innovation determines how rapidly consumers start to benefit from the new technology and firms start to make profits from it. Although Propositions 4 and 8 state that the aggregate rate of innovation remains unchanged with R\&D and RJV cartels, we show in the following discussion that their formation may still affect welfare adversely.

\subsection{R\&D Cartels}

Since the innovation arrives at the same time in expectation whether or not there is an $\mathrm{R} \& \mathrm{D}$ cartel, we have

$$
W^{C}-W^{*}=\frac{C\left[h\left(x^{C}\right) \frac{L}{r}-x^{C}\right]}{r+C h\left(x^{C}\right)+\left(R^{C}-C\right) h\left(x^{*}\right)}-C \cdot S .
$$

That is, the only difference between the welfare level with an R\&D cartel and the welfare level under $R \& D$ competition is the expected profits of the $R \& D$ cartel members themselves. This is because in both cases there is only one firm with the new technology in the market for the duration $T$ after the $R \& D$ race ends. This implies that consumer welfare is the same in expectation whether an $\mathrm{R} \& \mathrm{D}$ cartel is formed or not.

Since we know from Proposition 5 that R\&D cartels earn negative profits, (27) implies that they must be welfare decreasing. Hence, our analysis implies that in industries with free entry, R\&D cartels would never arise and antitrust policy towards them is irrelevant. Moreover, since they always decrease welfare, it is not desirable to subsidize R\&D cartels 
in order to make them profitable if there are outsider participants in the $\mathrm{R} \& \mathrm{D}$ race. We show in Section 8 that this conclusion may change if no outsiders choose to participate in the $R \& D$ race.

\subsection{RJV Cartels}

As in the case of R\&D cartels, since $J h\left(x^{J}\right)+\left(R^{J}-J\right) h\left(x^{*}\right)=R^{*} h\left(x^{*}\right)$, we have $W^{J}-W^{*}=\frac{J h\left(x^{J}\right) \frac{\Omega^{J}}{r}+\left(R^{J}-J-R^{*}\right) h\left(x^{*}\right) \frac{\Omega^{1}}{r}}{r+J h\left(x^{J}\right)+\left(R^{J}-J\right) h\left(x^{*}\right)}+J\left[\frac{h\left(x^{J}\right) \frac{J L^{J}}{r}-x^{J}}{r+J h\left(x^{J}\right)+\left(R^{J}-J\right) h\left(x^{*}\right)}-S\right]$.

That is, the difference between consumer welfare with an RJV cartel and under R\&D competition is that when an RJV cartel wins the race but before spillovers occur, there are $J$ firms with the new technology rather than only one. Hence, from (23) and (26) we can conclude that any profitable RJV cartel is also welfare improving if $\omega^{J} \geqslant \omega^{1}$. While one may expect consumer welfare to be increasing in the number of firms with access to the new technology, this may not always be the case with free entry and exit because increasing the number of firms with the new technology causes greater exit of firms with the old technology. Therefore, there may be fewer firms active in the product market when an RJV cartel wins the race than when a single firm does. In general, the net effect on consumer welfare of an RJV cartel can go either way depending on consumers' preferences and, hence, profitable RJV cartels may present a welfare trade-off between lower expected consumer welfare and higher expected profits.

This analysis implies that in industries with free entry, antitrust policy should pay careful attention to consumers' preferences and may, therefore, differ between industries. This contrasts with the policy prescriptions in the literature with barriers to entry and deterministic R\&D, where RJV cartels are always found to be welfare improving and, therefore, should be allowed. Miyagiwa and Ohno (2002) reach a more cautious conclusion. They find that it is both privately and socially optimal to form an RJV cartel if spillovers are fast and industry profits from sharing exceed those without sharing. ${ }^{19}$ In our model, however,

\footnotetext{
${ }^{19}$ In all other circumstances, they cannot guarantee that the private and social incentives to cooperate
} 
these two conditions together are neither necessary nor sufficient for the social and private incentives for RJV cartels to coincide.

The analysis also implies that there may be a case for subsiding unprofitable RJV cartels when they are welfare improving. This conclusion is a major departure from the results in the literature with deterministic $R \& D$ and barriers to entry, where Leahy and Neary (1997) conclude, for instance, that 'policy intervention to encourage cooperation is likely to be redundant whether or not it is desirable.' In the case of uncertain R\&D, Choi (1993) and Miyagiwa and Ohno (2002) do find room for subsidizing RJV cartels. In particular, Choi (1993) concludes that the social incentives to form RJVs always exceed the private incentives. However, Choi's (1993) results depend upon the assumption that sharing results increases product market competition. Such an assumption is not necessary for our conclusions, which are driven by the extra pressure put on members of cooperative arrangements by entrants. Although Miyagiwa and Ohno (2002) state that "there is no guarantee that the R\&D regime that the industry selects is the best for society," they do not identify when, if at all, government support would be desirable (p. 868). Our analysis takes us a step closer to this, with the surprising result that subsidies may be desirable in case of larger RJVs. Of course, not all such RJV cartels are welfare improving, but small RJV cartels where the members invest more per-firm than they do under R\&D competition should not require support.

\section{Cooperative $R \& D$ without $R \& D$ race outsiders}

In the analysis above, we have maintained the assumption that some outsiders always find it profitable to enter the $R \& D$ race in equilibrium. In this section, we provide some additional insights about cooperative $R \& D$ arrangements with free entry for the case where no outsiders choose to enter the race. We do this to address the potential concern that cooperation between firms in the $R \& D$ race may induce the exit of outsiders and, thus, reduce competition in the $R \& D$ race. Our results in this section show that the prospect of will coincide. 
cooperative $\mathrm{R} \& \mathrm{D}$ having this effect is no cause for concern.

The main difference in results from the case with outsiders concerns the aggregate rate of innovation. Surprisingly, we show in the following proposition that without outsiders, the aggregate rate of innovation with either an R\&D or an RJV cartel must be at least as high as it is under R\&D competition. This is because if outsiders find it unprofitable to enter the race, it must be because the cooperating firms have collectively invested enough to ensure any entry would be unprofitable.

Proposition 9 If there are no outsiders in equilibrium, the aggregate rate of innovation with an RED cartel or an RJV cartel must be at least as high as it is under RED competition.

Proof. We present the proof for the case of an R\&D cartel only since the case of an RJV cartel is identical. Suppose not. That is, suppose there are no outsiders in the R\&D race in equilibrium and the aggregate rate of innovation with an $\mathrm{R} \& \mathrm{D}$ cartel is lower than that under R\&D competition. We know that firms make zero profits under R\&D competition due to free entry. By Lemma 1, this implies that a profit-maximizing marginal entrant must be making a positive profit with an $R \& D$ cartel. Hence, it cannot be the case that there are no outsiders participating in the $R \& D$ race in equilibrium.

We show in Section 7 of the Appendix that most of the other results from the previous analysis continue to hold without $\mathrm{R} \& \mathrm{D}$ race outsiders. In particular, we show that all R\&D cartels are unprofitable and their per-firm investment is less than $x^{*}$. Moreover, there are critical values of $L^{J}$ above which RJV cartels invest more per-firm than $x^{*}$ and are profitable.

The only policy conclusion that is qualitatively different from those we reached in Section 7 is that it may be desirable to subsidize those $R \& D$ cartels which increase the aggregate rate of innovation since they increase consumer welfare in expectation. Hence, R\&D cartels without $\mathrm{R} \& \mathrm{D}$ race outsiders may present a welfare trade-off between lower profits and higher consumer welfare. To the best of our knowledge, the conclusion that subsidies for $R \& D$ cartels may be socially desirable is unique in the literature since they are always found to be profitable. 


\section{Conclusion}

We have analyzed the effects of cooperative R\&D in a model of free entry with stochastic $R \& D$ and an oligopolistic product market. Our findings account for the effects of entry and exit in $R \& D$ environments which have been missing from the literature to date. In contrast with the results in the literature, we have shown that $R \& D$ cartels are always unprofitable and never affect the aggregate rate of innovation adversely in equilibrium. RJV cartels, on the other hand, can be profitable depending on their size. Similar to R\&D cartels, they also never adversely affect the aggregate rate of innovation.

Both the standard approach of modelling cooperative R\&D with barriers to entry and our approach of free entry can be understood as opposite ends of a spectrum. This paper offers some guidance as to how the existing literature's policy prescriptions may change as entry conditions vary along this continuum. Our results indicate that it may be desirable to subsidize $\mathrm{R} \& \mathrm{D}$ cartels in cases when there are no outsider participants in the $\mathrm{R} \& \mathrm{D}$ race. Such a policy conclusion does not find support in the existing literature which assumes barriers to entry because a consistent conclusion of this literature is that $R \& D$ cartels are always profitable. The results also imply that since sharing of R\&D outcomes affects the equilibrium number of firms in the product market after the $\mathrm{R} \& \mathrm{D}$ race, the consumer welfare effects of RJV cartels are sensitive to the specification of consumers' preferences. Hence, the optimal antitrust treatment of cooperative R\&D arrangements may be different for different industries and a detailed analysis of demand may be required to determine the appropriate policy approach. Subsidies may be desirable in cases of larger RJVs since they are the ones which are less likely to be profitable.

Future research should consider the effects of input spillovers on cooperative research with free entry. The assumption of a Poisson discovery process used in this paper may not be appropriate for such a study because of the assumption that the research paths embarked upon by firms are independent. If one firm's research project benefits from the efforts of a rival firm, it would seem more reasonable to assume that their instantaneous probabilities of success should be correlated. 


\section{References}

[1] Amir, R. 2000. "Modelling Imperfectly Appropriable R\&D via Spillovers," International Journal of Industrial Organization, 18, 1013-1032.

[2] Amir, R. and J. Wooders. 1999. "Effects of One-Way Spillovers on Market Shares, Industry Price, Welfare, and R \& D Cooperation," Journal of Economics $\&$ Management Strategy, 8(2), 223-249.

[3] Amir, R. and J. Wooders. 2000. "One-Way Spillovers, Endogenous Innovator/Imitator Roles and Research Joint Ventures," Games and Economic Behavior, 31, 1-25.

[4] Anbarci, N., R. Lemke, and S. Roy. 2002. "Inter-firm Complementarities in R\&D: A Re-examination of the Relative Performance of Joint Ventures," International Journal of Industrial Organization, 20, 191-213.

[5] d'Aspremont, C. and A. Jacquemin. 1988. "Cooperative and Noncooperative R\&D in Duopoly with Spillovers," American Economic Review, 78, 1133-1137.

[6] Choi, J.P. 1993. "Cooperative R\&D with Product Market Competition," International Journal of Industrial Organization, 11, 553-571.

[7] Combs, K. 1992. "Cost Sharing vs. Multiple Research Projects in Cooperative R\&D," Economics Letters, 39, 353-357.

[8] Davidson, C. and A. Mukherjee. 2006. "Horizontal Mergers with Free Entry," International Journal of Industrial Organization, forthcoming.

[9] De Bondt, Raymond. 1997. "Spillovers and innovative activities," International Journal of Industrial Organization, 15, 1-28.

[10] Deneckere, R. and C. Davidson. 1985. "Incentives to Form Coalitions with Bertrand Competition," Rand Journal of Economics, 16, 473-486. 
[11] Denicolo, V. 2000. "Two-Stage Patent Races and Patent Policy," RAND Journal of Economics, 31(3), 488-501.

[12] Erkal, N. and D. Piccinin. 2006. "Horizontal Mergers with Free Entry in Differentiated Oligopolies," University of Melbourne, Department of Economics, Research Paper $\# 976$.

[13] Hauenschild, N. 2003. "On the Role of Input and Output Spillovers when R\&D Projects are Risky," International Journal of Industrial Organization, 21, 1065-1089.

[14] Kamien, M., E. Muller, and I. Zang. 1992. "Research Joint Ventures and R\&D Cartels," American Economic Review, 82, 1293-1306.

[15] Kamien, M. and I. Zang. 1993. "Competing Research Joint Ventures," Journal of Economics \& Management Strategy, 2, 23-40.

[16] Kamien, M. and I. Zang. 2000. "Meet me Halfway: Research Joint Ventures and Absorptive Capacity," International Journal of Industrial Organization, 18, 995-1012.

[17] Leahy, D. and P. Neary. 1997. "Public Policy Towards R\&D in Oligopolistic Industries," American Economic Review, 87, 642-662.

[18] Lee, T. and L. L. Wilde. 1980. "Market Structure and Innovation: A Reformulation," Quarterly Journal of Economics, 94, 429-436.

[19] Loury, G. 1979. "Market Structure and Innovation," Quarterly Journal of Economics, 93, 395-410.

[20] Mansfield, E. 1985. "How Rapidly Does New Technology Leak Out," The Journal of Industrial Economics, 34, 217-223.

[21] Mansfield, E., M. Schwartz, and S. Wagner. 1981. "Imitation Costs and Patents: An Empirical Study," Economic Journal, 91, 907-918. 
[22] Martin, S. 2002. "Spillovers, Appropriability, and R\&D," Journal of Economics, 75, $1-22$.

[23] Miyagiwa, K. and Y. Ohno. 2002. "Uncertainty, Spillovers, and Cooperative R\&D," International Journal of Industrial Organization, 20, 855-876.

[24] Motta, M. 1992. "Cooperative R\&D and Vertical Product Differentiation," International Journal of Industrial Organization, 10, 643-661.

[25] Poyago-Theotoky, J. 1995. "Equilibrium and Optimal Size of a Research Joint Venture in an Oligopoly with Spillovers," Journal of Industrial Economics, 43, 209-226.

[26] Reinganum, J. 1985. "Innovation and Industry Evolution," Quarterly Journal of Economics, 100, 81-99.

[27] Salant, S. and G. Shaffer. 1998. "Optimal Asymmetric Strategies in Research Joint Ventures," International Journal of Industrial Organization, 16, 195-208.

[28] Salant, S. W., S. Switzer, and R. J. Reynolds. 1983. "Losses from Horizontal Merger: The Effects of an Exogenous Change in Industry Structure on Cournot-Nash Equilibrium," Quarterly Journal of Economics, 98, 185-199.

[29] Suzumura, K. 1992. "Cooperative and Noncooperative R\&D in an Oligopoly with Spillovers," American Economic Review, 82, 1307-1320.

[30] Vonortas, N. 1994. "Inter-firm Cooperation with Imperfectly Appropriable Research," International Journal of Industrial Organization, 12, 413-435.

[31] Ziss, S. 1994. "Strategic R\&D with Spillovers, Collusion, and Welfare," Journal of Industrial Economics, 42, 375-397. 


\section{Appendix}

\section{Proof of Proposition 2}

Let $\bar{x}^{C}$ and $\bar{x}^{O}$ stand for the investment levels which satisfy the first-order conditions of the cartel participants and the outsider firms, respectively, for a given number of cartel participants, $C$, and outsiders, $O=R-C$. We first show that, as in the case of R\&D competition, $\bar{x}^{C}$ and $\bar{x}^{O}$ are both increasing in $R$ by invoking a stability condition.

For given values of $C$ and $R$, let $\bar{G}^{C}$ and $\bar{H}^{C}$ represent the first-order conditions given in (14) and (15). $\bar{G}^{C}$ and $\bar{H}^{C}$ implicitly define $\bar{x}^{C}$ and $\bar{x}^{O}$. Totally differentiating and applying Cramer's Rule gives

$$
\frac{d \bar{x}^{C}}{d R}=\frac{-\frac{\partial \bar{G}^{C}}{\partial R} \frac{\partial \bar{H}^{C}}{\partial \bar{x}^{O}}+\frac{\partial \bar{G}^{C}}{\partial \bar{x}^{O}} \frac{\partial \bar{H}^{C}}{\partial R}}{\frac{\partial \bar{G}^{C}}{\partial \bar{x}^{C}} \frac{\partial \bar{H}^{C}}{\partial \bar{x}^{O}}-\frac{\partial \bar{G}^{C}}{\partial \bar{x}^{O}} \frac{\partial \bar{H}^{C}}{\partial \bar{x}^{C}}}
$$

and

$$
\frac{d \bar{x}^{O}}{d R}=\frac{-\frac{\partial \bar{G}^{C}}{\partial \bar{x}^{C}} \frac{\partial \bar{H}^{C}}{\partial R}+\frac{\partial \bar{G}^{C}}{\partial R} \frac{\partial \bar{H}^{C}}{\partial \bar{x}^{C}}}{\frac{\partial \bar{G}^{C}}{\partial \bar{x}^{C}} \frac{\partial \bar{H}^{C}}{\partial \bar{x}^{O}}-\frac{\partial \bar{G}^{C}}{\partial \bar{x}^{O}} \frac{\partial \bar{H}^{C}}{\partial \bar{x}^{C}}}
$$

Following Reinganum (1985), we assume that the denominators of both expressions can be interpreted as a stability condition and, hence, are positive. ${ }^{20}$

The numerator of (A.1) is equal to

$$
-h\left(\bar{x}^{O}\right)\left(h^{\prime}\left(\bar{x}^{C}\right) \frac{L}{r}-1\right)\left[\begin{array}{c}
h^{\prime \prime}\left(\bar{x}^{O}\right)\left[L+\bar{x}^{O}+\left((R-C-1) h\left(\bar{x}^{O}\right)+C h\left(\bar{x}^{C}\right)\right) \frac{L}{r}\right] \\
-h^{\prime}\left(\bar{x}^{O}\right)\left(h^{\prime}\left(\bar{x}^{O}\right) \frac{L}{r}-1\right)
\end{array}\right]>0 .
$$

The numerator of (A.2) is equal to

$$
h\left(\bar{x}^{O}\right)\left(h^{\prime}\left(\bar{x}^{O}\right) \frac{L}{r}-1\right)\left[\begin{array}{c}
-h^{\prime \prime}\left(\bar{x}^{C}\right)\left(L+C \bar{x}^{C}+(R-C) h\left(\bar{x}^{O}\right) \frac{L}{r}\right) \\
+C h^{\prime}\left(\bar{x}^{C}\right)\left(h^{\prime}\left(\bar{x}^{C}\right) \frac{L}{r}-1\right)
\end{array}\right]>0 .
$$

Hence, we have $\frac{d \bar{x}^{C}}{d R}$ and $\frac{d \bar{x}^{O}}{d R}>0$.

It follows that for any given outsider firm, $\bar{\alpha}_{i}=C h\left(\bar{x}^{C}\right)+(R-C-1) h\left(\bar{x}^{O}\right)$ must also be increasing in $R$. Since by Lemma 1 the maximized profits of an outsider firm are decreasing in $\alpha_{i}$, we can conclude that there exists a free entry equilibrium where $R^{C}$

\footnotetext{
${ }^{20}$ See p. 92 in Reinganum (1985).
} 
denotes the number of participants in the $\mathrm{R} \& \mathrm{D}$ race and all outsider participants earn zero profits.

\section{Proof of Proposition 3}

The first step is to show that $x^{C}<x^{O}$. Consider the first derivatives for the cartel's and a typical outsider's optimization problems. After imposing symmetry, these are given by

$$
\widetilde{G}^{C} \equiv h^{\prime}\left(\widetilde{x}^{C}\right)\left[L+C \widetilde{x}^{C}+\frac{L}{r}\left(R^{C}-C\right) h\left(x^{O}\right)\right]-\left[r+C h\left(\widetilde{x}^{C}\right)+\left(R^{C}-C\right) h\left(x^{O}\right)\right]
$$

and

$$
\widetilde{H}^{C} \equiv h^{\prime}\left(x^{O}\right)\left[L+x^{O}+\frac{L}{r}\left[\begin{array}{c}
\left(R^{C}-C-1\right) h\left(x^{O}\right) \\
+C h\left(\widetilde{x}^{C}\right)
\end{array}\right]\right]-\left[\begin{array}{c}
r+C h\left(\widetilde{x}^{C}\right) \\
+\left(R^{C}-C\right) h\left(x^{O}\right)
\end{array}\right],
$$

where $x^{O}$ and $\widetilde{x}^{C}$ stand for the equilibrium investment level of an outsider firm and any symmetric investment level chosen by the cartel members, respectively. In equilibrium, $\widetilde{x}^{C}=x^{C}$. Note that

$\frac{\partial\left(\widetilde{G}^{C}-\widetilde{H}^{C}\right)}{\partial \widetilde{x}^{C}}=h^{\prime \prime}\left(\widetilde{x}^{C}\right)\left[L+C \widetilde{x}^{C}+\frac{L}{r}\left(R^{C}-C\right) h\left(x^{O}\right)\right]-h^{\prime}\left(\widetilde{x}^{C}\right)\left[C h^{\prime}\left(x^{O}\right) \frac{L}{r}-1\right]<0$.

Moreover, $\widetilde{G}^{C}-\widetilde{H}^{C}$ evaluated at the point where $\widetilde{x}^{C}=x^{O}$ yields

$$
-(C-1) h^{\prime}\left(x^{O}\right)\left[h\left(x^{O}\right) \frac{L}{r}-x^{O}\right]<0 .
$$

Hence, whenever $\widetilde{G}^{C}-\widetilde{H}^{C}=0$, which must be the case in equilibrium, we must have $x^{C}<x^{O}$.

We next show that $x^{O}=x^{*}$, which implies that if there are any active outsiders in the $\mathrm{R} \& \mathrm{D}$ race, each member of the $\mathrm{R} \& \mathrm{D}$ cartel invests $x^{C}<x^{*}$. To see this, note that all active outsider firms in the $R \& D$ race earn zero profits in equilibrium. Hence, by Lemma 1 , an outsider firm $i$ must face the same value of $\alpha_{i}$ as it does under R\&D competition. This implies that it solves the same maximization problem as it does under R\&D competition and invests $x^{*}$ whether or not there is an $\mathrm{R} \& \mathrm{D}$ cartel participating in the $\mathrm{R} \& \mathrm{D}$ race also. 


\section{Proof of Proposition 6}

Let $\bar{x}^{J}$ and $\bar{x}^{O}$ stand for the investment levels which satisfy (19) and (20), respectively, for a given number of cartel participants, $J$, and outsiders, $O=R-J$. We start by showing that $\bar{x}^{J}$ and $\bar{x}^{O}$ are both increasing in $R$ by invoking a stability condition analogous to the one in the proof of Proposition 2.

For given values of $J$ and $R$, let $\bar{G}^{J}$ and $\bar{H}^{J}$ represent the first-order conditions given in (19) and (20). $\bar{G}^{J}$ and $\bar{H}^{J}$ implicitly define $\bar{x}^{J}$ and $\bar{x}^{O}$. Totally differentiating and applying Cramer's Rule gives

$$
\frac{d \bar{x}^{J}}{d R}=\frac{-\frac{\partial \bar{G}^{J}}{\partial R} \frac{\partial \bar{H}^{J}}{\partial \bar{x}^{O}}+\frac{\partial \bar{G}^{J}}{\partial \bar{x}^{O}} \frac{\partial \bar{H}^{J}}{\partial R}}{\frac{\partial \bar{G}^{J}}{\partial \bar{x}^{J}} \frac{\partial \bar{H}^{J}}{\partial \bar{x}^{O}}-\frac{\partial \bar{G}^{J}}{\partial \bar{x}^{O}} \frac{\partial \bar{H}^{J}}{\partial \bar{x}^{J}}}
$$

and

$$
\frac{d \bar{x}^{O}}{d R}=\frac{-\frac{\partial \bar{G}^{J}}{\partial \bar{x}^{J}} \frac{\partial \bar{H}^{J}}{\partial R}+\frac{\partial \bar{G}^{J}}{\partial R} \frac{\partial \bar{H}^{J}}{\partial \bar{x}^{J}}}{\frac{\partial \bar{G}^{J}}{\partial \bar{x}^{J}} \frac{\partial \bar{H}^{J}}{\partial \bar{x}^{O}}-\frac{\partial \bar{G}^{J}}{\partial \bar{x}^{O}} \frac{\partial \bar{H}^{J}}{\partial \bar{x}^{J}}} .
$$

Following Reinganum (1985), we assume that the denominators of both expressions can be interpreted as a stability condition and, hence, are positive. ${ }^{21}$

The numerator of (A.9) is equal to

$$
-h\left(\bar{x}^{O}\right)\left(J h^{\prime}\left(\bar{x}^{J}\right) \frac{L^{J}}{r}-1\right)\left[\begin{array}{c}
h^{\prime \prime}\left(\bar{x}^{O}\right)\left[L+\bar{x}^{O}+\frac{L}{r}\left((R-J-1) h\left(\bar{x}^{O}\right)+C h\left(\bar{x}^{J}\right)\right)\right] \\
-h^{\prime}\left(\bar{x}^{O}\right)\left(\frac{L}{r} h^{\prime}\left(\bar{x}^{O}\right)-1\right)
\end{array}\right]>0 .
$$

The numerator of (A.10) is equal to

$$
J h\left(\bar{x}^{O}\right)\left(h^{\prime}\left(\bar{x}^{O}\right) \frac{L}{r}-1\right)\left[\begin{array}{c}
-h^{\prime \prime}\left(\bar{x}^{J}\right)\left[L^{J}+\bar{x}^{J}+\frac{L^{J}}{r}(R-J) h\left(\bar{x}^{O}\right)\right] \\
+h^{\prime}\left(\bar{x}^{J}\right)\left(J h^{\prime}\left(\bar{x}^{J}\right) \frac{L^{J}}{r}-1\right)
\end{array}\right]>0 .
$$

Hence, we have $\frac{d \bar{x}^{J}}{d R}$ and $\frac{d \bar{x}^{O}}{d R}>0$.

It follows that for any given outsider firm, $\bar{\alpha}_{i}=J h\left(\bar{x}^{J}\right)+(R-J-1) h\left(\bar{x}^{O}\right)$ must also be increasing in $R$. Since by Lemma 1 the maximized profits of an outsider firm are decreasing in $\alpha_{i}$, we can conclude that there exists a free entry equilibrium where $R^{J}$ denotes the number of participants in the $\mathrm{R} \& \mathrm{D}$ race and all outsider participants earn zero profits.

\footnotetext{
${ }^{21}$ See p. 92 in Reinganum (1985).
} 


\section{Proof of Lemma 2}

The free entry equilibrium investment levels and number of firms are implicitly defined by (19), (20), and (21). Let $G^{J}, H^{J}$, and $Z^{J}$ stand for these three conditions. Totally differentiating and applying Cramer's Rule gives us

$$
\frac{d x^{J}}{d L^{J}}=\frac{\frac{\partial G^{J}}{\partial L^{J}}\left[\frac{\partial Z^{J}}{\partial x^{O}} \frac{\partial H^{J}}{\partial R}-\frac{\partial Z^{J}}{\partial R} \frac{\partial H^{J}}{\partial x^{O}}\right]}{\frac{\partial Z^{J}}{\partial x^{J}}\left[\frac{\partial G^{J}}{\partial x^{O}} \frac{\partial H^{J}}{\partial R}-\frac{\partial G^{J}}{\partial R} \frac{\partial H^{J}}{\partial x^{O}}\right]-\frac{\partial Z^{J}}{\partial x^{O}}\left[\frac{\partial G^{J}}{\partial x^{J}} \frac{\partial H^{J}}{\partial R}-\frac{\partial G^{J}}{\partial R} \frac{\partial H^{J}}{\partial x^{J}}\right]+\frac{\partial Z^{J}}{\partial R}\left[\frac{\partial G^{J}}{\partial x^{J}} \frac{\partial H^{J}}{\partial x^{O}}-\frac{\partial G^{J}}{\partial x^{O}} \frac{\partial H^{J}}{\partial x^{J}}\right]} .
$$

The stability condition implies that $\frac{\partial G^{J}}{\partial x^{J}} \frac{\partial H^{J}}{\partial x^{O}}>\frac{\partial G^{J}}{\partial x^{O}} \frac{\partial H^{J}}{\partial x^{J}}$. Since $\frac{\partial G^{J}}{\partial x^{J}}<0, \frac{\partial G^{J}}{\partial x^{O}}>0$, and $\frac{\partial H^{J}}{\partial x^{J}}>0$, we must have $\frac{\partial H^{J}}{\partial x^{O}}<0$. Furthermore, $\frac{\partial G^{J}}{\partial L^{J}}, \frac{\partial H^{J}}{\partial R}, \frac{\partial G^{J}}{\partial R}, \frac{\partial G^{J}}{\partial x^{O}}$ and $\frac{\partial H^{J}}{\partial x^{J}}$ are $>0$ while $\frac{\partial G^{J}}{\partial x^{J}}, \frac{\partial H^{J}}{\partial x^{O}}, \frac{\partial Z^{J}}{\partial R}, \frac{\partial Z^{J}}{\partial x^{O}}$ and $\frac{\partial Z^{J}}{\partial x^{J}}$ are $<0$. Hence, both the numerator and denominator of (A.13) are negative, and we have $\frac{d x^{J}}{d L^{J}}>0$.

To prove that equilibrium RJV cartel profits are monotonically increasing in $L^{J}$, note that

$$
\frac{d\left(J V^{J}\right)}{d L^{J}}=\frac{\partial\left(J V^{J}\right)}{\partial L^{J}}+\frac{\partial\left(J V^{J}\right)}{\partial \alpha^{J}} \frac{\partial \alpha^{J}}{\partial L^{J}}
$$

where $V^{J}$ stands for the per-firm profit level with an RJV cartel and $\alpha^{J}=\left(R^{J}-J\right) x^{O}$. The first term on the right hand side is positive and the first part of the second term is negative by inspection of (17). From Lemma 1 we know that in a free entry equilibrium, the outsiders must face the same value of $\alpha_{i}$ regardless of the value of $L^{J}$. This implies that $\frac{d R^{J}}{d L^{J}}<0$ since $x^{O}=x^{*}$ and $\frac{d x^{J}}{d L^{J}}>0$, as established above. Hence, the second part of the second term is negative also.

\section{Proof of Lemma 3}

Substituting for $L^{J}=\frac{L}{J}$ in the first derivative of (13) with respect to $x_{i}$ reveals that if $C=J$, i.e., if an R\&D cartel and an RJV cartel both have the same number of firms, the per-firm investment level is the same under both types of cooperative arrangements. Similarly, substituting for $L^{J}=\frac{L}{J}$ in the equilibrium payoff level shows that the profits are also the same under the two types of cooperative arrangements. Hence, the results for 
$L^{J}=\frac{L}{J}$ follow from Proposition 3 and Proposition 5.

Consider now the case where $L^{J}=L$. The first step is to show that $x^{J}>x^{O}$. Consider the first derivatives for the cartel's and a typical outsider's optimization problems. After imposing symmetry, these are given by

$$
\widetilde{G}^{J} \equiv J h^{\prime}\left(\widetilde{x}^{J}\right)\left[L^{J}+\widetilde{x}^{J}+\frac{L^{J}}{r}\left(R^{J}-J\right) h\left(x^{O}\right)\right]-\left[r+J h\left(\widetilde{x}^{J}\right)+\left(R^{J}-J\right) h\left(x^{O}\right)\right]
$$

and

$$
\widetilde{H}^{J} \equiv h^{\prime}\left(x^{O}\right)\left[L+x^{O}+\frac{L}{r}\left[\begin{array}{c}
\left(R^{J}-J-1\right) h\left(x^{O}\right) \\
+J h\left(\widetilde{x}^{J}\right)
\end{array}\right]\right]-\left[\begin{array}{c}
r+J h\left(\widetilde{x}^{J}\right) \\
+\left(R^{J}-J\right) h\left(x^{O}\right)
\end{array}\right],
$$

where $x^{O}$ and $\widetilde{x}^{J}$ stand for the equilibrium investment level of an outsider firm and any symmetric investment level chosen by the cartel members, respectively. In equilibrium, $\widetilde{x}^{J}=x^{J}$. Note that

$$
\frac{\partial\left(\widetilde{G}^{J}-\widetilde{H}^{J}\right)}{\partial \widetilde{x}^{J}}=J h^{\prime \prime}\left(\widetilde{x}^{J}\right)\left[L+\widetilde{x}^{J}+\frac{L}{r}\left(R^{J}-J\right) h\left(x^{O}\right)\right]-J h^{\prime}\left(\widetilde{x}^{J}\right)\left[h^{\prime}\left(x^{O}\right) \frac{L}{r}-1\right]<0 .
$$

Moreover, $\widetilde{G}^{J}-\widetilde{H}^{J}$ evaluated at the point where $\widetilde{x}^{J}=x^{O}$ yields

$$
(J-1) h^{\prime}\left(x^{O}\right)\left[L+x^{O}+\frac{L}{r}\left(R^{J}-J-1\right) h\left(x^{O}\right)\right]>0 .
$$

Hence, whenever $\widetilde{G}^{J}-\widetilde{H}^{J}=0$, which must be the case in equilibrium, we must have $x^{J}>x^{O}$.

We next show that any active outsider participant in the $\mathrm{R} \& \mathrm{D}$ race must invest $x^{*}$. All active outsider firms in the $R \& D$ race earn zero profits in equilibrium. By Lemma 1, this implies that an outsider firm $i$ must face the same value of $\alpha_{i}$ as it does under $\mathrm{R} \& \mathrm{D}$ competition. Hence, it solves the same maximization problem as it does under R\&D competition and invests $x^{*}$. This result together with the analysis above implies that if there are any active outsider participants in the R\&D race, each member of the RJV cartel invests $x^{J}>x^{*}$ in equilibrium.

To see that the RJV cartel earns positive profits, note that if we hold the outsiders' investments constant at $x^{*}$ and decrease the RJV cartel's investment to $x^{*}$, the RJV cartel's 
per firm profits are

$$
\frac{h\left(x^{*}\right) \frac{J L}{r}-x^{*}}{r+J h\left(x^{*}\right)+\left(R^{J}-J\right) h\left(x^{*}\right)}-S
$$

and an outsider firm earns

$$
\frac{h\left(x^{*}\right) \frac{L}{r}-x^{*}}{r+J h\left(x^{*}\right)+\left(R^{J}-J\right) h\left(x^{*}\right)}-S,
$$

which is clearly less. However, the outsider firm would be earning strictly positive profits, since there would be fewer firms in total making the same per-firm investments as under R\&D competition. Hence, the RJV cartel would also be making strictly positive profits. Since the RJV cartel chooses $x^{J}$ to maximize its joint profits given the outside firms choose $x^{*}$, it must earn even higher profits in equilibrium.

\section{$6 \quad$ Proof of Proposition 7}

We know from Lemma 3 that when $L^{J}=\frac{L}{J}$, the members of the RJV earn less than they would under R\&D competition, and when $L^{J}=L$, they earn more than they would under R\&D competition. Hence, given Lemma 2, there must exist a critical value $\widehat{L}^{J} \in\left(\frac{L}{J}, L\right)$ above which the profits with an RJV cartel of size $J$ are higher than they are under R\&D competition and below which they are lower.

Similarly, we know from Lemma 3 that when $L^{J}=\frac{L}{J}$, the members of the RJV invest less than they would under $\mathrm{R} \& \mathrm{D}$ competition and when $L^{J}=L$, they invest more than they would under R\&D competition. Hence, given Lemma 2, there must exist a critical value $\widetilde{L}^{J} \in\left(\frac{L}{J}, L\right)$ above which the per-firm investment level with an RJV cartel of size $J$ is higher than it is under $\mathrm{R} \& \mathrm{D}$ competition and below which it is lower.

To prove that $\widetilde{L}^{J}>\widehat{L}^{J}$, we evaluate the profitability of an RJV cartel when $L^{J}=\widetilde{L}^{J}$ and show that it is positive. When $L^{J}=\widetilde{L}^{J}$, the RJV cartel's equilibrium per-firm investment is $x^{*}$ by definition. Note that each outsider participant in the $\mathrm{R} \& \mathrm{D}$ race in equilibrium earns

$$
\frac{h\left(x^{*}\right) \frac{L}{r}-x^{*}}{r+J h\left(x^{*}\right)+\left(R^{J}-J\right) h\left(x^{*}\right)}-S=0
$$


while each member of the RJV cartel earns

$$
\frac{h\left(x^{*}\right) \frac{J \widetilde{L}^{J}}{r}-x^{*}}{r+J h\left(x^{*}\right)+\left(R^{J}-J\right) h\left(x^{*}\right)}-S .
$$

Subtracting (A.21) from (A.22) yields

$$
\frac{h\left(x^{*}\right)\left[\frac{J \widetilde{L}^{J}-L}{r}\right]}{r+J h\left(x^{*}\right)+\left(R^{J}-J\right) h\left(x^{*}\right)}>0
$$

since $\widetilde{L}^{J}>L$.

\section{Cooperative $R \& D$ without $R \& D$ race outsiders}

In this section, we show to what extent the results stated in Propositions 3, 5, and 7 extend to the case where no outsiders find it profitable to enter the $R \& D$ race.

Proposition 10 When there are no active outsider firms in the REDD race in equilibrium, the per-firm investment level with an REDD cartel is lower than the per-firm investment level under RED competition. However, RED cartels are always unprofitable.

Proof. We first show that $x^{C}<x^{*}$ in equilibrium. When there are outsider participants in the $\mathrm{R} \& \mathrm{D}$ race, we know from Proposition 3 that $x^{C}<x^{O}=x^{*}$ and from Proposition 4 that $R^{*} h\left(x^{*}\right)=O h\left(x^{*}\right)+C h\left(x^{C}\right)$, where $R^{*} h\left(x^{*}\right)$ is the equilibrium aggregate rate of innovation under R\&D competition and $O$ is the equilibrium number of outsider participants in the $\mathrm{R} \& \mathrm{D}$ race in the presence of an $\mathrm{R} \& \mathrm{D}$ cartel. Hence, as $O \rightarrow 0$ from above, it must be the case that $C>R^{*}$. Let $\widehat{C}$ stand for the value of $C$ such that $C h\left(x^{C}\right)=R^{*} h\left(x^{*}\right)$. We have $x^{C}(\widehat{C})<x^{*}$.

For $C>\widehat{C}$, there are no outsider participants in the $\mathrm{R} \& \mathrm{D}$ race. The first-order condition of the $R \& D$ cartel reduces to

$$
h^{\prime}\left(x^{C}\right)\left[L+C x^{C}\right]-\left[r+C h\left(x^{C}\right)\right]=0 .
$$

Using the implicit function theorem we have

$$
\frac{\partial x^{C}}{\partial C}=-\frac{h^{\prime}\left(x^{C}\right) x^{C}-h\left(x^{C}\right)}{h^{\prime \prime}\left(x^{C}\right)\left[L+C x^{C}\right]} .
$$


The denominator is clearly negative because $h\left(x^{C}\right)$ is concave. The numerator is equal to zero at $x^{C}=0$ and is strictly decreasing in $x^{C}$ for all $x^{C}>0$. Hence, $\frac{\partial x^{C}}{\partial C}<0$ for all $C>\widehat{C}$ and we can conclude that $x^{C}<x^{*}$ when there are no active outsiders in the $\mathrm{R} \& \mathrm{D}$ race.

To show that R\&D cartels are unprofitable when there are no outsider participants in the $\mathrm{R} \& \mathrm{D}$ race, note first that we know from Proposition 5 that as $C$ approaches $\widehat{C}$ from below, the per-firm profit level of the R\&D cartel members is negative. For all $C>\widehat{C}$, we can use (13) to write the equilibrium per-firm R\&D cartel payoff as

$$
V^{C}=\frac{h\left(x^{C}\right) \frac{L}{r}-x^{C}}{r+C h\left(x^{C}\right)}-S .
$$

Applying the envelope theorem, we have $\frac{\partial V^{C}}{\partial C}<0$. Hence, $C V^{C}<0$ for all values of $C$ such that there are no outsiders in equilibrium.

Proposition 11 When there are no active outsider firms in the R\&D race in equilibrium, members of an RJV cartel invest higher (lower) amounts per-firm than they do under RED competition for values of $J$ such that $L^{J}>\widetilde{L}^{J}(J) \in\left(\frac{L}{J}, L\right)\left(L^{J}<\widetilde{L}^{J}(J) \in\left(\frac{L}{J}, L\right)\right)$. Members of an RJV cartel earn higher (lower) profits than they do under RधD competition for values of $J$ such that $L^{J}>\widehat{L}^{J}(J) \in\left(\frac{L}{J}, L\right)\left(L^{J}<\widehat{L}^{J}(J) \in\left(\frac{L}{J}, L\right)\right)$.

Proof. First, note that when there are no outsiders in the R\&D race, we have

$$
\frac{\partial x^{J}}{\partial L^{J}}=-\frac{J h^{\prime}\left(x^{J}\right)}{J h^{\prime \prime}\left(x^{J}\right)\left[L^{J}+x^{J}\right]}>0
$$

and

$$
\frac{d\left(J V^{J}\right)}{d L^{J}}>0
$$

Hence, the per-firm investment level and the joint profits of an RJV cartel are monotonically increasing in $L^{J}$.

To get the result stated in the proposition, we next show that when $L^{J}=\frac{L}{J}, \mathrm{R} \& \mathrm{D}$ cartels invest less than $x^{*}$ per firm and are unprofitable, and when $L^{J}=L, \mathrm{R} \& \mathrm{D}$ cartels invest more than $x^{*}$ per firm and are profitable.

When $L^{J}=\frac{L}{J}$, the first-order condition and equilibrium profit function of an RJV cartel are identical to those of an R\&D cartel of the same size. We know from Proposition 10 that 
$\mathrm{R} \& \mathrm{D}$ cartels invest less than $x^{*}$ per firm and are unprofitable. Hence, the same must be true of RJV cartels when $L^{J}=\frac{L}{J}$.

When $L^{J}=L$, if there are outsider participants in the $\mathrm{R} \& \mathrm{D}$ race, we know from Lemma 3 that $x^{J}>x^{*}$ and from Proposition 8 that $R^{*} h\left(x^{*}\right)=O h\left(x^{*}\right)+J h\left(x^{J}\right)$. Hence, as $O \rightarrow 0$ from above, it must be the case that $J<R^{*}$. Holding $L^{J}$ fixed at $L$, let $\widehat{J}$ stand for the value of $J$ such that $J h\left(x^{J}\right)=R^{*} h\left(x^{*}\right)$. We have $x^{J}(\widehat{J})>x^{*}$.

For $J>\widehat{J}$, there are no outsider participants in the R\&D race. The first-order condition of the RJV cartel reduces to

$$
J h^{\prime}\left(x^{J}\right)\left[L+x^{J}\right]-\left[r+J h\left(x^{J}\right)\right]=0
$$

Using the implicit function theorem we have

$$
\frac{\partial x^{J}}{\partial J}=-\frac{h^{\prime}\left(x^{J}\right)\left[L+x^{J}\right]-h\left(x^{J}\right)}{J h^{\prime \prime}\left(x^{J}\right)\left[L+x^{J}\right]} .
$$

The denominator is clearly negative. Since the first-order condition implies that the numerator is equal to $\frac{r}{J}>0$, we have $\frac{\partial x^{J}}{\partial J}>0$. Hence, we can conclude that $x^{J}>x^{*}$ when there are no active $R \& D$ race outsiders.

To show that the members of an RJV cartel earn more than they do under R\&D competition, note first that we know from Lemma 3 that as $J$ approaches $\widehat{J}$ from below, profits are higher with an RJV cartel. When there are no outsiders in the R\&D race, each cartel member's payoff is

$$
V^{J}=\frac{h\left(x^{J}\right) \frac{J L}{r}-x^{J}}{r+J h\left(x^{J}\right)}-S
$$

Applying the envelope theorem gives

$$
\frac{\partial V^{J}}{\partial J}=\frac{r h\left(x^{J}\right) \frac{L}{r}+h\left(x^{J}\right) x^{J}}{\left[r+J h\left(x^{J}\right)\right]^{2}}>0 .
$$

Hence, $J V^{J}<0$ for all values of $J$ such that there are no outsiders in equilibrium. 